\title{
Theoretical study of the Stark broadening for Mg IV spectral lines of astrophysical interest
}

\author{
I. de Andrés-García, ${ }^{1}$ C. You, ${ }^{2}$ A. Alonso-Medina ${ }^{1 \star}$ and C. Colón ${ }^{1 \star}$ \\ ${ }^{1}$ Física Aplicada, E.T.S.I.D. Industrial, Universidad Politécnica de Madrid, Ronda de Valencia 3, E-28012 Madrid, Spain \\ ${ }^{2}$ Química Industrial y Polímeros, E.T.S.I.D. Industrial, Universidad Politécnica de Madrid, Ronda de Valencia 3, E-28012 Madrid, Spain
}

Accepted 2016 August 3. Received 2016 July 27; in original form 2016 May 27

\begin{abstract}
Emission lines of $\mathrm{Mg}$ IV have been detected in the Far Ultraviolet Spectroscopic Explorer (FUSE) spectrum of LS V $+46^{\circ} 21$ star and in the Space Telescope Imaging Spectrograph (STIS) spectrum of $\mathrm{BD}+28^{\circ} 4211 \mathrm{star}$. This fact justifies our interest in providing spectroscopic parameters of $\mathrm{Mg}$ IV. Stark broadening parameters for 169 spectral lines of $\mathrm{Mg}$ IV have been calculated by using the Griem semi-empirical approach. The matrix elements used in these calculations has been determined from 13 configurations of $\operatorname{Mg}$ IV: $2 s^{1} 2 p^{6}, 2 s^{2} 2 p^{4} n s(n=$ $3-5), 2 \mathrm{~s}^{2} 2 \mathrm{p}^{4} \mathrm{nd}(n=3-5)$ and $2 \mathrm{~s}^{2} 2 \mathrm{p}^{4} 5 \mathrm{~g}$ for even parity and $2 \mathrm{~s}^{2} 2 \mathrm{p}^{5}, 2 \mathrm{~s}^{2} 2 \mathrm{p}^{4} \mathrm{np}(n=3,4)$ and $2 \mathrm{~s}^{2} 2 \mathrm{p}^{4} \mathrm{nf}(n=4,5)$ for odd parity. Our calculations were made by using the Cowan code. Data are presented for an electron density of $10^{17} \mathrm{~cm}^{-3}$ and temperatures $\mathrm{T}=1.0-10.0\left(10^{4} \mathrm{~K}\right)$. Also we present calculated values of transition probabilities for 30 spectral lines and radiative lifetimes corresponding to its upper levels. These values were analysed using the data found in the literature. Theoretical trends of the Stark broadening parameters versus the temperature for several lines of astrophysical interest are presented.
\end{abstract}

Key words: atomic data - atomic processes.

\section{INTRODUCTION}

As is well known, atomic physics, astrophysics and engineering need extensive knowledge of the parameters of Stark broadening of spectral lines of atoms and ions. These parameters along with the transition probabilities and the half-lives are essential to the determination of the abundances of the different species in different stars. In addition the diagnosis of industrial plasmas in different engineering processes is also dependent on these parameters.

Triply ionized magnesium, $\mathrm{Mg}$ IV, is a member of the electronic sequence of fluorine. Its configuration in the lowest energy state is $2 \mathrm{~s}^{2} 2 \mathrm{p}^{5}$. Lines of $\mathrm{Mg}$ IV $(140.17 \AA, 140.52 \AA, 146.95 \AA, 171.66 \AA$ and $180.61 \AA$ ) have been detected in the solar spectra and have been used for application to high spectral resolution measurements of astrophysical plasmas (Doschek \& Cowan 1984). Several lines of $\mathrm{Mg}$ IV have been detected by Far Ultraviolet Spectroscopic Explorer (FUSE) and Space Telescope Imaging Spectrograph (STIS). In Rauch et al. (2007) in order to determine the photospheric parameters of LS V $+46^{\circ} 21$ star identified some lines of several atomic and ionic species including the Mg Iv. 15 weak UV lines, including the strongest $1683.0 \AA$ A line of Mg IV were identified by the authors. In its conclusions, the authors indicate that some discrepancies between his theoretical results and the experimental data can be due to the lack of reliable atomic and line broadening data. Recently, Latour et al. (2013) presented a detailed analysis of the UV spectrum

\footnotetext{
^E-mail: aurelia.alonso@upm.es (AAM); cristobal.colon@upm.es (CC)
}

of the calibration star $\mathrm{BD}+28^{\circ} 4211$ using high-quality spectra obtained with the FUSE. Authors determined the abundances of 11 elements, including Magnesium, by using seven UV lines of $\mathrm{Mg}$ IV. In the paper, the wavelength of these lines is not listed. We think that these facts justify the need to provide data on the broadening of $\mathrm{Mg}$ IV spectral lines detected and other lines that by being very close, in wavelength, to the observed lines could add new information.

Energy levels and wavelengths of Mg IV was carried out by Johannesson, Lundström \& Minnhagen (1972), Johannesson \& Lundström (1973), and Artru \& Kaufman (1972, 1973). These compilations complete the tables presented by Moore (1958).

There are not experimental values for the transition probabilities and oscillator strengths in the bibliography, only theoretical values can be found. Gruzdev (1971) calculates values of wavelengths, oscillator strengths and energy levels for Mg IV obtained by using the Coulomb approximation. Later, Fawcett (1984) presents theoretical wavelengths, oscillator strengths and energy levels using the Cowan code and the energy level experimental data of Artru \& Kaufman (1972). A similar study was carried out by Biémont (1985). Values taking into account correlations effects were obtained by Johnson \& Kingston (1987). In Froese Fischer and Tachiev (2004) present ab initio transition probabilities.

There are in the bibliography experimental values of decay for some lines of Mg IV. In 1973, Lundin et al. (1973) presented the decay measurement for the line of $171.7 \AA$ in a beam-foil spectroscopy experiment with Magnesium. The authors indicated that in this experiment the $\mathrm{Mg}_{\text {IV }}$ lines can be blend from $\mathrm{Mg}_{\text {III }}$ spectral 


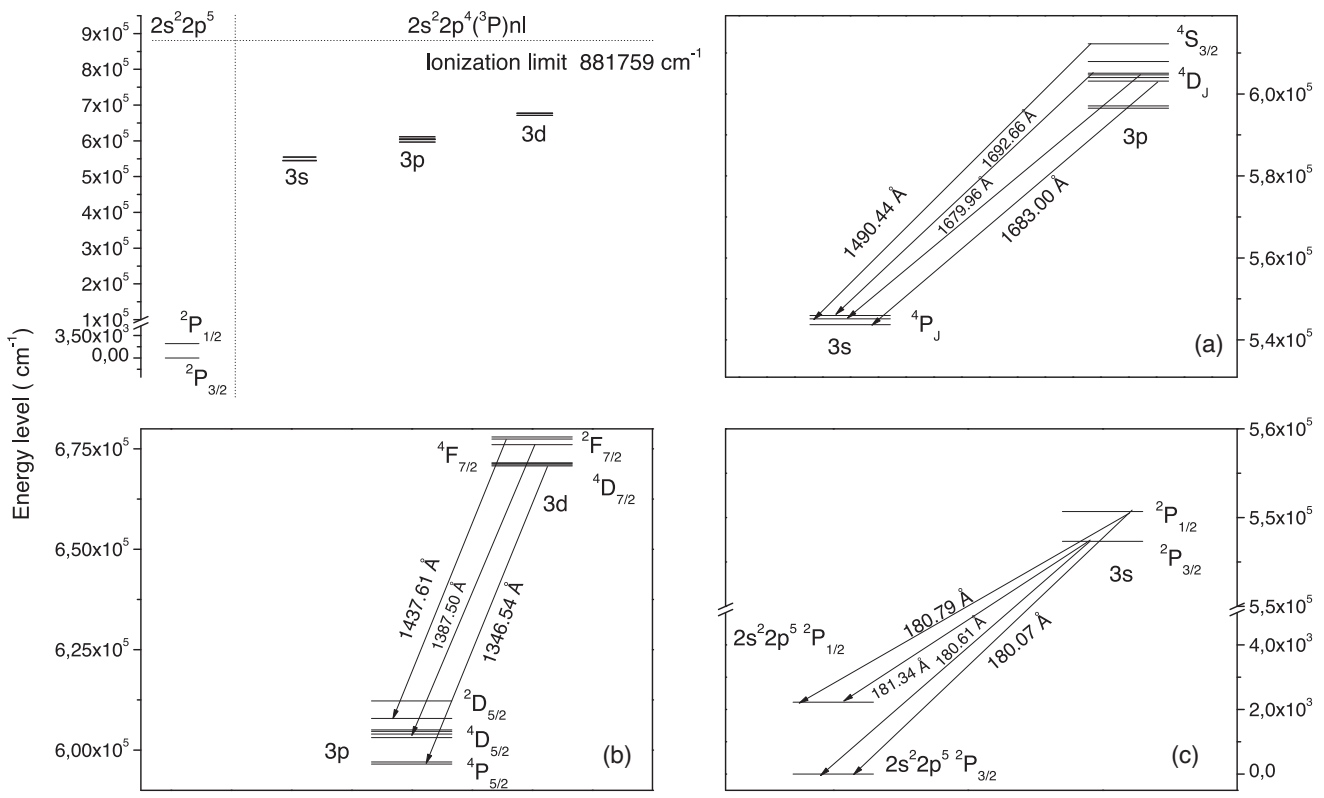

Figure 1. Partial Grotrian diagram of the Mg IV energy levels (Moore 1958, Artru \& Kaufman 1972 and Johannesson et al. 1972). In (a-c) we present some lines of astrophysical interest: (a) lines of $2 s^{2} 2 p^{4}\left({ }^{3} \mathrm{P}\right) 3 \mathrm{~s}-2 \mathrm{~s}^{2} 2 \mathrm{p}^{4}\left({ }^{3} \mathrm{P}\right) 3 \mathrm{p}$, (b) lines of $2 \mathrm{~s}^{2} 2 \mathrm{p}^{4}\left({ }^{3} \mathrm{P}\right) 3 \mathrm{p}-2 \mathrm{~s}^{2} 2 \mathrm{p}^{4}\left({ }^{3} \mathrm{P}\right) 3 \mathrm{~d}$, (c) lines of $2 \mathrm{~s}^{2} 2 \mathrm{p}^{5}-2 \mathrm{~s}^{2} 2 \mathrm{p}^{4}\left({ }^{3} \mathrm{P}\right) 3 \mathrm{~s}$.

Table 1. Transition probabilities, $\mathrm{A}_{\mathrm{ij}}$, of several spectral lines arising from $2 \mathrm{~s}^{2} 2 \mathrm{p}^{4} \mathrm{nl}$ and $2 \mathrm{~s} 2 \mathrm{p}^{6}$ configurations of Mg IV. We also show the radiative lifetimes of these configurations.

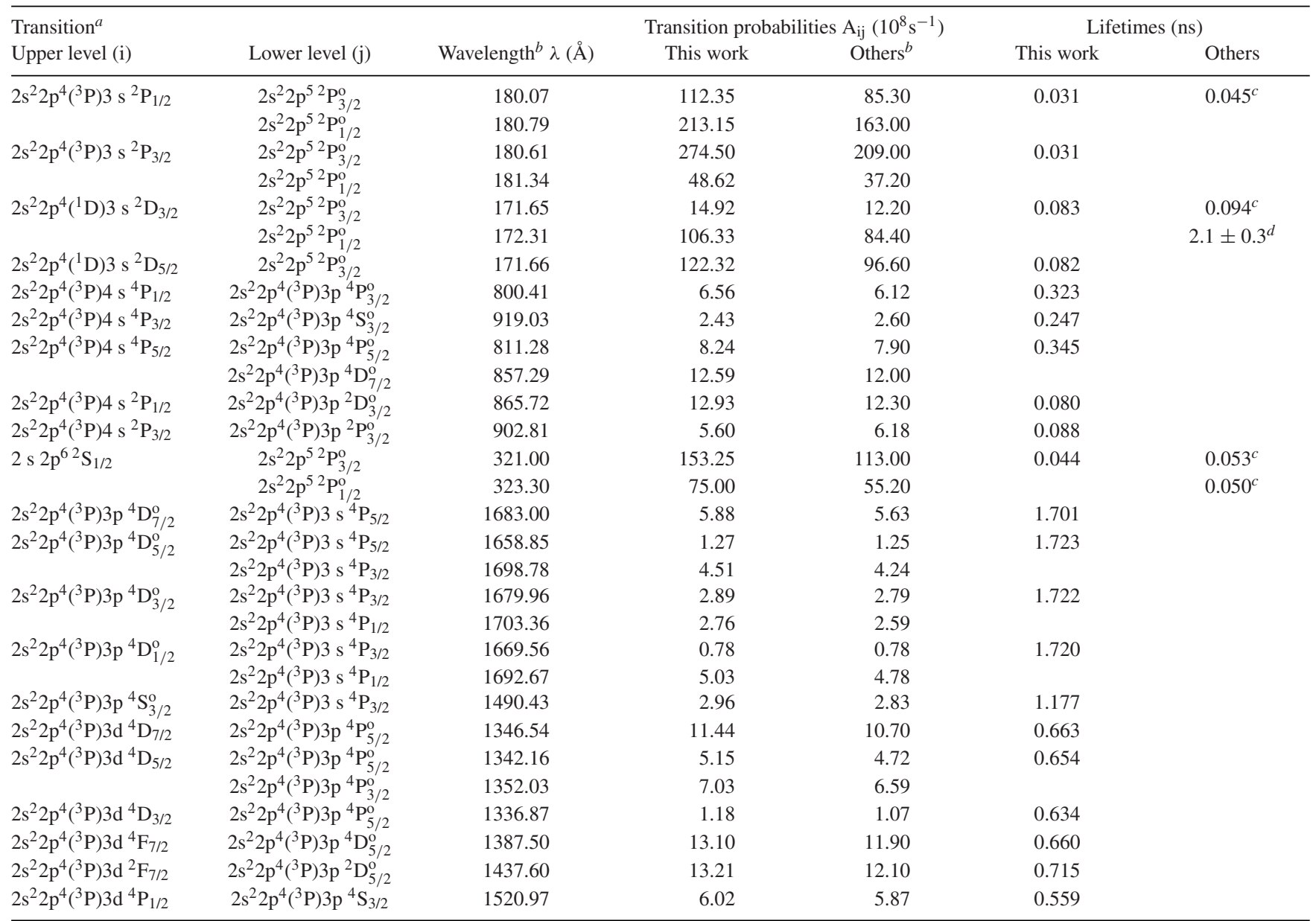

${ }^{a}$ Johannesson et al. (1972).

${ }^{b}$ Kramida et al. (2013).

${ }^{c}$ Buchet et al. (1980). See discussion in the text.

${ }^{d}$ Lundin et al. (1973). See discussion in the text. 
Table 2. Mg Iv $2 \mathrm{~s}^{2} 2 \mathrm{p}^{5}-2 \mathrm{~s}^{2} 2 \mathrm{p}^{4}\left({ }^{3} \mathrm{P}\right) 3 \mathrm{~s}$ and $2 \mathrm{~s}^{2} 2 \mathrm{p}^{5}-2 \mathrm{~s}^{2} 2 \mathrm{p}^{4}\left({ }^{1} \mathrm{D}\right) 3 \mathrm{~s}$ line-widths (FWHM), $\omega$ (pm), and shifts, $d$ (pm), normalized to $\mathrm{Ne}=10^{17} \mathrm{~cm}^{-3}$. We present values only for six lines. The remaining up to 10 lines are present online.

\begin{tabular}{|c|c|c|c|c|c|c|}
\hline $\mathrm{N}_{\mathrm{o}}$ & Transition array & Multiplet & Wavelength $(\AA)^{a}$ & $\mathrm{~T}\left(10^{4} \mathrm{~K}\right)$ & $\omega(\mathrm{pm})$ & $d(\mathrm{pm})$ \\
\hline \multirow[t]{4}{*}{2} & \multirow[t]{4}{*}{$2 s^{2} 2 p^{5}-2 s^{2} 2 p^{4}\left({ }^{3} P\right) 3 s$} & \multirow[t]{4}{*}{${ }^{2} \mathrm{P}_{3 / 2}^{\mathrm{o}}-{ }^{2} \mathrm{P}_{1 / 2}$} & \multirow[t]{4}{*}{180.07} & 1 & 0.02 & -0.02 \\
\hline & & & & 3 & 0.01 & -0.01 \\
\hline & & & & 5 & 0.01 & -0.01 \\
\hline & & & & 10 & 0.01 & -0.01 \\
\hline \multirow[t]{4}{*}{3} & \multirow[t]{4}{*}{$2 s^{2} 2 p^{5}-2 s^{2} 2 p^{4}\left({ }^{3} P\right) 3 s$} & \multirow{4}{*}{${ }^{2} \mathrm{P}_{1 / 2}^{\mathrm{o}}-{ }^{2} \mathrm{P}_{1 / 2}$} & \multirow[t]{4}{*}{180.79} & 1 & 0.02 & -0.02 \\
\hline & & & & 3 & 0.01 & -0.01 \\
\hline & & & & 5 & 0.01 & -0.01 \\
\hline & & & & 10 & 0.00 & -0.00 \\
\hline \multirow[t]{4}{*}{4} & \multirow[t]{4}{*}{$2 s^{2} 2 p^{5}-2 s^{2} 2 p^{4}\left({ }^{3} P\right) 3 s$} & \multirow[t]{4}{*}{${ }^{2} \mathrm{P}_{3 / 2}^{\mathrm{o}}-{ }^{2} \mathrm{P}_{3 / 2}$} & \multirow[t]{4}{*}{180.61} & 1 & 0.03 & -0.03 \\
\hline & & & & 3 & 0.02 & -0.02 \\
\hline & & & & 5 & 0.01 & -0.01 \\
\hline & & & & 10 & 0.01 & -0.01 \\
\hline \multirow[t]{4}{*}{5} & \multirow[t]{4}{*}{$2 s^{2} 2 p^{5}-2 s^{2} 2 p^{4}\left({ }^{3} P\right) 3 s$} & \multirow[t]{4}{*}{${ }^{2} \mathrm{P}_{1 / 2}^{\mathrm{o}}-{ }^{2} \mathrm{P}_{3 / 2}$} & \multirow[t]{4}{*}{181.34} & 1 & 0.03 & -0.03 \\
\hline & & & & 3 & 0.02 & -0.02 \\
\hline & & & & 5 & 0.01 & -0.01 \\
\hline & & & & 10 & 0.01 & -0.01 \\
\hline \multirow[t]{4}{*}{6} & \multirow[t]{4}{*}{$2 s^{2} 2 p^{5}-2 s^{2} 2 p^{4}\left({ }^{1} D\right) 3 s$} & \multirow[t]{4}{*}{${ }^{2} \mathrm{P}_{3 / 2}^{\mathrm{o}}-{ }^{2} \mathrm{D}_{3 / 2}$} & \multirow[t]{4}{*}{171.65} & 1 & 0.03 & -0.03 \\
\hline & & & & 3 & 0.02 & -0.02 \\
\hline & & & & 5 & 0.01 & -0.01 \\
\hline & & & & 10 & 0.01 & -0.01 \\
\hline \multirow[t]{4}{*}{7} & \multirow[t]{4}{*}{$2 s^{2} 2 p^{5}-2 s^{2} 2 p^{4}\left({ }^{1} D\right) 3 s$} & \multirow[t]{4}{*}{${ }^{2} \mathrm{P}_{1 / 2}^{\mathrm{o}}-{ }^{2} \mathrm{D}_{3 / 2}$} & \multirow[t]{4}{*}{172.31} & 1 & 0.03 & -0.03 \\
\hline & & & & 3 & 0.01 & -0.01 \\
\hline & & & & 5 & 0.01 & -0.01 \\
\hline & & & & 10 & 0.01 & -0.01 \\
\hline
\end{tabular}

Note. A positive shift is red.

${ }^{a}$ Kramida et al. (2013).

lines. Later, in a similar experiment carried out by Buchet, BuchetPoulizac \& Ceyzeriat (1980), experimental decays for three levels of $\mathrm{Mg}$ IV were measured.

We did not find, in the literature, experimental values for the broadening of Mg IV lines. However Ber̆gman et al. (1996) observed shifts in the resonant lines attributed to the quadratic Stark effects. There are, in the literature, theoretical values for four $\mathrm{Mg}$ IV multiplets (Dimitrijević 1988). These values are included in the STARK-B Database (2013).

The aim of this paper is to cover this lack of Stark broadening data, and therefore we present theoretical values of Stark broadening parameters for 169 lines of $\mathrm{Mg}$ IV arising from $2 \mathrm{~s}^{2} 2 \mathrm{p}^{4} \mathrm{~ns}$ ( $n$ $=3,4), 2 s^{2} 2 p^{4} 3 p$ and $2 s^{2} 2 p^{4} 3 d$ configurations. These calculations were performed in the same way in which these authors have calculated similar parameters. As example in the Mg III, Colón, MorenoDíaz \& Alonso-Medina (2013) and Moreno-Díaz, Alonso-Medina \& Colón (2014), the results were obtained by using a semi-classical approach. The Stark broadening parameters are displayed for a set of temperatures ranging of $10000-100000 \mathrm{~K}$ and an electron density of $10^{17} \mathrm{~cm}^{-3}$. Moreover, it has been explicitly stated in this work the dependence of the broadening and shifts versus the temperature. To evaluate the consistency of our calculations we have compared the lifetimes that are deduced from it with the few experimental lifetimes found in the literature.

\section{THEORETICAL CALCULATIONS}

We used in our calculations a semi-empirical impact approximation. This approach was obtained in Griem (1968) taking into account the Baranger's (1958) original formulation. This procedure has been used by the authors, e.g., Alonso-Medina \& Herrán (1996), Colón \& Alonso-Medina (2002), Alonso-Medina et al. (2010, 2014), Colón et al. (2006, 2013) and recently de Andrés-García, Alonso-Medina $\&$ Colón (2016). For this purpose we used the following expressions:

$$
\begin{aligned}
\varpi_{\mathrm{se}} \approx & 8\left(\frac{\pi}{3}\right)^{3 / 2} \frac{\hbar}{m a_{0}} N_{e}\left(\frac{E_{H}}{k T}\right)^{1 / 2}\left[\sum_{i^{\prime}}\left|\left\langle i^{\prime}|\boldsymbol{r}| i\right\rangle\right|^{2} g_{\mathrm{se}}\left(\frac{E}{\Delta E_{i^{\prime} i}}\right)\right. \\
& \left.+\sum_{f^{\prime}}\left|\left\langle f^{\prime}|\boldsymbol{r}| f\right\rangle\right|^{2} g_{\mathrm{se}}\left(\frac{E}{\Delta E_{f^{\prime} f}}\right)\right] \\
d \approx & -8\left(\frac{\pi}{3}\right)^{3 / 2} \frac{\hbar}{m a_{0}} N_{e}\left(\frac{E_{H}}{k T}\right)^{1 / 2} \\
& \times\left[\sum_{i^{\prime}}\left(\frac{\Delta E_{i^{\prime} i}}{\left|\Delta E_{i^{\prime} i}\right|}\right)\left|\left\langle i^{\prime}|\boldsymbol{r}| i\right\rangle\right|^{2} g_{\mathrm{sh}}\left(\frac{E}{\Delta E_{i^{\prime} i}}\right)\right. \\
& \left.-\sum_{f^{\prime}}\left(\frac{\Delta E_{f^{\prime} f}}{\left|\Delta E_{f^{\prime} f}\right|}\right)\left|\left\langle f^{\prime}|\boldsymbol{r}| f\right\rangle\right|^{2} g_{\mathrm{sh}}\left(\frac{E}{\Delta E_{f^{\prime} f}}\right)\right]
\end{aligned}
$$

where, $\mathrm{d}$ and $\omega_{\text {se }}$ represent the Stark line shifts and width, respectively in angular frequency units, $E=3 / 2 k T$ means the energy of the perturbing electron, $E_{\mathrm{H}}$ is the hydrogen ionization energy, $N_{e}$ is the free electron density and $T$ is the electron temperature. The initial and final levels of the transitions are denoted by $i$ and $f$, respectively. To express these parameters in units of wavelength we used $\omega=\omega_{\text {se }} \lambda^{2} /(\pi c)$.

As seen in previous work by these same authors (Moreno-Díaz et al. 2014 and de Andrés-García et al. 2016) we use an effective Gaunt factor, $g_{\text {se }}$ and $g_{\text {sh }}$ proposed by Seaton (1962) and Van 
Table 3. $\operatorname{Mg}$ IV $2 s^{2} 2 p^{4}\left({ }^{3} \mathrm{P}\right) 3 \mathrm{~s}-2 \mathrm{~s}^{2} 2 \mathrm{p}^{4}\left({ }^{3} \mathrm{P}\right) 3 \mathrm{p}$ line-widths (FWHM), $\omega(\mathrm{pm})$, and shifts, $d(\mathrm{pm})$, normalized to $\mathrm{Ne}=10^{17} \mathrm{~cm}^{-3}$. We present values only for eight lines. The remaining up to 45 lines are present online.

\begin{tabular}{|c|c|c|c|c|c|c|}
\hline $\mathrm{N}_{\mathrm{o}}$ & Transition array & Multiplet & Wavelength $(\AA)^{a}$ & $\mathrm{~T}\left(10^{4} \mathrm{~K}\right)$ & $\omega(\mathrm{pm})$ & $d(\mathrm{pm})$ \\
\hline \multirow[t]{4}{*}{8} & \multirow[t]{4}{*}{$2 s^{2} 2 p^{4}\left({ }^{3} P\right) 3 s-2 s^{2} 2 p^{4}\left({ }^{3} P\right) 3 p$} & \multirow[t]{4}{*}{${ }^{4} \mathrm{P}_{5 / 2}-{ }^{4} \mathrm{D}_{7 / 2}^{\mathrm{o}}$} & \multirow[t]{4}{*}{1683.00} & 1 & 8.47 & -5.61 \\
\hline & & & & 3 & 4.89 & -3.24 \\
\hline & & & & 5 & 3.79 & -2.51 \\
\hline & & & & 10 & 1.89 & -1.18 \\
\hline \multirow[t]{4}{*}{9} & \multirow[t]{4}{*}{$2 s^{2} 2 p^{4}\left({ }^{3} P\right) 3 s-2 s^{2} 2 p^{4}\left({ }^{3} P\right) 3 p$} & \multirow[t]{4}{*}{${ }^{4} \mathrm{P}_{5 / 2}-{ }^{4} \mathrm{D}_{5 / 2}^{\mathrm{o}}$} & \multirow[t]{4}{*}{1658.85} & 1 & 6.97 & -4.89 \\
\hline & & & & 3 & 4.03 & -2.82 \\
\hline & & & & 5 & 3.11 & -2.19 \\
\hline & & & & 10 & 1.59 & -1.06 \\
\hline \multirow[t]{4}{*}{10} & \multirow[t]{4}{*}{$2 s^{2} 2 p^{4}\left({ }^{3} P\right) 3 s-2 s^{2} 2 p^{4}\left({ }^{3} P\right) 3 p$} & \multirow[t]{4}{*}{${ }^{4} \mathrm{P}_{3 / 2}-{ }^{4} \mathrm{D}_{5 / 2}^{\mathrm{o}}$} & \multirow[t]{4}{*}{1698.78} & 1 & 6.20 & -4.01 \\
\hline & & & & 3 & 3.58 & -2.32 \\
\hline & & & & 5 & 2.66 & -1.69 \\
\hline & & & & 10 & 1.37 & -0.82 \\
\hline \multirow[t]{4}{*}{13} & \multirow[t]{4}{*}{$2 s^{2} 2 p^{4}\left({ }^{3} P\right) 3 s-2 s^{2} 2 p^{4}\left({ }^{3} P\right) 3 p$} & \multirow[t]{4}{*}{${ }^{4} \mathrm{P}_{3 / 2}-{ }^{4} \mathrm{D}_{3 / 2}^{\mathrm{o}}$} & \multirow[t]{4}{*}{1679.96} & 1 & 4.77 & -3.34 \\
\hline & & & & 3 & 2.75 & -1.93 \\
\hline & & & & 5 & 2.03 & -1.39 \\
\hline & & & & 10 & 1.08 & -0.73 \\
\hline \multirow[t]{4}{*}{14} & \multirow[t]{4}{*}{$2 s^{2} 2 p^{4}\left({ }^{3} P\right) 3 s-2 s^{2} 2 p^{4}\left({ }^{3} P\right) 3 p$} & \multirow{4}{*}{${ }^{4} \mathrm{P}_{1 / 2}-{ }^{4} \mathrm{D}_{3 / 2}^{\mathrm{o}}$} & \multirow[t]{4}{*}{1703.36} & 1 & 3.78 & -2.31 \\
\hline & & & & 3 & 2.18 & -1.34 \\
\hline & & & & 5 & 1.56 & -0.91 \\
\hline & & & & 10 & 0.82 & -0.45 \\
\hline \multirow[t]{4}{*}{15} & \multirow[t]{4}{*}{$2 s^{2} 2 p^{4}\left({ }^{3} P\right) 3 s-2 s^{2} 2 p^{4}\left({ }^{3} P\right) 3 p$} & \multirow[t]{4}{*}{${ }^{4} \mathrm{P}_{3 / 2}-{ }^{4} \mathrm{D}_{1 / 2}^{\mathrm{o}}$} & \multirow[t]{4}{*}{1669.56} & 1 & 3.43 & -2.73 \\
\hline & & & & 3 & 1.98 & -1.58 \\
\hline & & & & 5 & 1.43 & -1.12 \\
\hline & & & & 10 & 0.82 & -0.64 \\
\hline \multirow[t]{4}{*}{16} & \multirow[t]{4}{*}{$2 s^{2} 2 p^{4}\left({ }^{3} P\right) 3 s-2 s^{2} 2 p^{4}\left({ }^{3} P\right) 3 p$} & \multirow[t]{4}{*}{${ }^{4} \mathrm{P}_{1 / 2}-{ }^{4} \mathrm{D}_{1 / 2}^{\mathrm{o}}$} & \multirow[t]{4}{*}{1692.67} & 1 & 2.42 & -1.70 \\
\hline & & & & 3 & 1.40 & -0.98 \\
\hline & & & & 5 & 0.96 & -0.63 \\
\hline & & & & 10 & 0.55 & -0.37 \\
\hline \multirow[t]{4}{*}{26} & $2 s^{2} 2 p^{4}\left({ }^{3} P\right) 3 s-2 s^{2} 2 p^{4}\left({ }^{3} P\right) 3 p$ & ${ }^{4} \mathrm{P}_{3 / 2}-{ }^{4} \mathrm{~S}_{3 / 2}^{\mathrm{o}}$ & 1490.43 & 1 & 3.83 & -2.76 \\
\hline & & & & 3 & 2.21 & -1.60 \\
\hline & & & & 5 & 1.63 & -1.16 \\
\hline & & & & 10 & 0.88 & -0.68 \\
\hline
\end{tabular}

Note. A positive shift is red.

${ }^{a}$ Kramida et al. (2013).

Regemorter (1962). We have used a fit to the values given by Van Regemorter in his table I for the effective Gaunt factor. As it is well known, Griem (1968), a factor larger than 1.5 between calculated and experimental values can be expected with the use of this effective Gaunt factor. As can be seen in the expressions, we need obtain a set of matrix elements including all relevant transitions. On the purpose of obtaining the matrix elements required in these expressions, we could have used the Coulomb approximation, but we prefer to use an intermediate coupling scheme (IC). The wave functions were calculated by using relativistic Hartree-Fock approach (HFR) as well as configuration interaction which provides not only transition probabilities for lines allowed in LS coupling but also included so-called forbidden transitions.

13 configurations of $\mathrm{Mg}$ IV were used in this work in which: $2 \mathrm{~s}^{1} 2 \mathrm{p}^{6}, 2 \mathrm{~s}^{2} 2 \mathrm{p}^{4} \mathrm{~ns}(n=3-5), 2 \mathrm{~s}^{2} 2 \mathrm{p}^{4}$ nd $(n=3-5)$ and $2 \mathrm{~s}^{2} 2 \mathrm{p}^{4} 5 \mathrm{~g}$ are even parity and $2 \mathrm{~s}^{2} 2 \mathrm{p}^{5}, 2 \mathrm{~s}^{2} 2 \mathrm{p}^{4} \mathrm{np}(n=3,4)$ and $2 \mathrm{~s}^{2} 2 \mathrm{p}^{4} \mathrm{nf}(n=4,5)$ are odd parity. We used the standard method of least-square fitting of experimental energy levels included in the Cowan's programs (1981). For these calculations we used all the experimental levels shown in the Moore table (1958) and the values given by Johannesson et al. (1972) and Artru \& Kaufman (1972), data collected by Kaufman \& Martin (1991). Fig. 1 illustrated a partial energy levels diagram of the $\mathrm{Mg}$ IV and some lines of astrophysical interest in three windows details.
In our case we have $55+103$ experimental levels and Cowan's code has over 168 parameters. Since not all parameters can be adjusted, we followed the Cowan's indications. We used, in the calculations a factor of 0.85 in order to scale down the values of $F_{k}, G_{k}$ and $R_{k}$ excluded in the fitting processes (no experimental configurations We used the HFR ab initio values for the spinorbit integrals $\zeta_{\mathrm{nl}}$ of small numerical values (these values were not adjusted in the fitting procedures). Our parameters values are similar to the values presented by Johannesson et al. (1972) and Artru \& Kaufman (1972).

The matrix elements required in the above expressions, transition probabilities and lifetimes have been calculated from the wave functions obtained in this work. To test its validity we should compare the transition probabilities and lifetimes with experimental values. There are no experimental transition probabilities to compare with our results. There are only theoretical values deduced with different theoretical approaches that are not directly comparable: ab initio approximations are optimized for calculating energy levels. The process of adjusting to experimental theoretical levels can make changes in transition probabilities causing discrepancies in transition probabilities of the weaker lines. There is the possibility to compare our lifetime values with the experimental values. We present in Table I, described in Section 3, the experimental values available in the bibliography compared with our theoretical values. 
Table 4. $\mathrm{Mg}$ Iv $2 \mathrm{~s}^{2} 2 \mathrm{p}^{4}\left({ }^{3} \mathrm{P}\right) 3 \mathrm{p}-2 \mathrm{~s}^{2} 2 \mathrm{p}^{4}\left({ }^{3} \mathrm{P}\right) 3 \mathrm{~d}$ line-widths (FWHM), $\omega(\mathrm{pm})$, and shifts, $d(\mathrm{pm})$, normalized to $\mathrm{Ne}=10^{17} \mathrm{~cm}^{-3}$. We present values only for seven lines. The remaining up to 93 lines are present online.

\begin{tabular}{|c|c|c|c|c|c|c|}
\hline $\mathrm{N}_{\mathrm{o}}$ & Transition array & Multiplet & Wavelength $(\AA)^{a}$ & $\mathrm{~T}\left(10^{4} \mathrm{~K}\right)$ & $\omega(\mathrm{pm})$ & $d(\mathrm{pm})$ \\
\hline \multirow[t]{4}{*}{1} & \multirow[t]{4}{*}{$2 s^{2} 2 p^{4}\left({ }^{3} P\right) 3 p-2 s^{2} 2 p^{4}\left({ }^{3} P\right) 3 d$} & \multirow{4}{*}{${ }^{4} \mathrm{P}_{5 / 2}^{\mathrm{o}}-{ }^{4} \mathrm{D}_{7 / 2}$} & \multirow[t]{4}{*}{1346.54} & 1 & 6.07 & -2.15 \\
\hline & & & & 3 & 3.50 & -1.24 \\
\hline & & & & 5 & 2.65 & -1.03 \\
\hline & & & & 10 & 0.86 & -0.04 \\
\hline \multirow[t]{4}{*}{4} & \multirow[t]{4}{*}{$2 s^{2} 2 p^{4}\left({ }^{3} P\right) 3 p-2 s^{2} 2 p^{4}\left({ }^{3} P\right) 3 d$} & \multirow{4}{*}{${ }^{4} \mathrm{P}_{5 / 2}^{\mathrm{o}}-{ }^{4} \mathrm{D}_{5 / 2}$} & \multirow[t]{4}{*}{1342.16} & 1 & 5.13 & -1.86 \\
\hline & & & & 3 & 2.96 & -1.07 \\
\hline & & & & 5 & 2.23 & -0.90 \\
\hline & & & & 10 & 0.76 & -0.05 \\
\hline \multirow[t]{4}{*}{5} & \multirow[t]{4}{*}{$2 s^{2} 2 p^{4}\left({ }^{3} P\right) 3 p-2 s^{2} 2 p^{4}\left({ }^{3} P\right) 3 d$} & \multirow{4}{*}{${ }^{4} \mathrm{P}_{3 / 2}^{\mathrm{o}}-{ }^{4} \mathrm{D}_{5 / 2}$} & \multirow[t]{4}{*}{1352.03} & 1 & 4.39 & -1.54 \\
\hline & & & & 3 & 2.53 & -0.89 \\
\hline & & & & 5 & 1.90 & -0.76 \\
\hline & & & & 10 & 0.61 & -0.03 \\
\hline \multirow[t]{4}{*}{9} & \multirow[t]{4}{*}{$2 s^{2} 2 p^{4}\left({ }^{3} P\right) 3 p-2 s^{2} 2 p^{4}\left({ }^{3} P\right) 3 d$} & \multirow{4}{*}{${ }^{4} \mathrm{P}_{5 / 2}^{\mathrm{o}}-{ }^{4} \mathrm{D}_{3 / 2}$} & \multirow[t]{4}{*}{1336.87} & 1 & 4.19 & -1.56 \\
\hline & & & & 3 & 2.42 & -0.90 \\
\hline & & & & 5 & 1.81 & -0.76 \\
\hline & & & & 10 & 0.66 & -0.06 \\
\hline \multirow[t]{4}{*}{20} & \multirow[t]{4}{*}{$2 s^{2} 2 p^{4}\left({ }^{3} P\right) 3 p-2 s^{2} 2 p^{4}\left({ }^{3} P\right) 3 d$} & \multirow[t]{4}{*}{${ }^{4} \mathrm{D}_{5 / 2}^{\mathrm{o}}-{ }^{4} \mathrm{~F}_{7 / 2}$} & \multirow[t]{4}{*}{1387.50} & 1 & 6.75 & -2.59 \\
\hline & & & & 3 & 3.90 & -1.49 \\
\hline & & & & 5 & 3.02 & -1.16 \\
\hline & & & & 10 & 0.99 & -0.20 \\
\hline \multirow[t]{4}{*}{31} & \multirow[t]{4}{*}{$2 s^{2} 2 p^{4}\left({ }^{3} P\right) 3 p-2 s^{2} 2 p^{4}\left({ }^{3} P\right) 3 d$} & \multirow[t]{4}{*}{${ }^{2} \mathrm{D}_{5 / 2}^{\mathrm{o}}-{ }^{2} \mathrm{~F}_{7 / 2}$} & \multirow[t]{4}{*}{1437.60} & 1 & 7.44 & -2.87 \\
\hline & & & & 3 & 4.29 & -1.66 \\
\hline & & & & 5 & 3.33 & -1.28 \\
\hline & & & & 10 & 1.18 & -0.20 \\
\hline \multirow[t]{4}{*}{38} & \multirow[t]{4}{*}{$2 s^{2} 2 p^{4}\left({ }^{3} P\right) 3 p-2 s^{2} 2 p^{4}\left({ }^{3} P\right) 3 d$} & \multirow[t]{4}{*}{${ }^{4} \mathrm{~S}_{3 / 2}^{\mathrm{o}}-{ }^{4} \mathrm{P}_{1 / 2}$} & \multirow[t]{4}{*}{1520.97} & 1 & 3.47 & -1.54 \\
\hline & & & & 3 & 2.00 & -0.89 \\
\hline & & & & 5 & 1.55 & -0.69 \\
\hline & & & & 10 & 0.61 & -0.26 \\
\hline
\end{tabular}

Note. A positive shift is red.

${ }^{a}$ Kramida et al. (2013).

\section{RESULTS AND DISCUSSION}

We contrast our values of transition probabilities of several resonant lines and lines of astrophysical interest of $\mathrm{Mg}$ IV with other theoretical values calculated with different methods and collected in NIST. This comparison is presented in Table 1. As can be seen both theoretical sets of values are mutually compatible. We also present, in Table 1, the lifetimes of the upper levels of the studied lines and whenever possible were compared with the experimental values availables. We found only three experimental values in the literature. Lundin et al. (1973) presents experimental value of decay of $2.1 \pm 0.3 \mathrm{~ns}$ for the $\mathrm{Mg}$ IV $2 \mathrm{p}^{4}\left({ }^{1} \mathrm{D}\right) 3 \mathrm{~s}^{2} \mathrm{D}$ level. The authors indicated that this value could be affected by cascades that suffocate a very fast initial decay. Also they indicated that this value could be affected by $\mathrm{Mg}$ III transitions. Later Buchet et al. (1980) made experimental measurements for the $\operatorname{Mg}$ IV $2 \mathrm{p}^{4}\left({ }^{1} \mathrm{D}\right) 3 \mathrm{~s}^{2} \mathrm{D}, 2 \mathrm{p}^{4}\left({ }^{3} \mathrm{P}\right)$ $3 \mathrm{~s}^{2} \mathrm{P}$ and $2 \mathrm{~s} 2 \mathrm{p}^{62} \mathrm{~S}$ levels. In all cases their direct measurements for the line decays were about $2.5 \mathrm{~ns}$. After correcting the cascades, the values presented for these levels (of about 4 per cent of direct value) are in agreement well with our theoretical calculations as can be seen in the abovementioned table.

Our values for the Stark line-width and line shift are displayed for a set of temperatures ranging of $10000-100000 \mathrm{~K}$ and an electron density of $10^{17} \mathrm{~cm}^{-3}$ in Tables 2-4 In text it is included only those corresponding to the spectral lines with astrophysical interest (on line we included the complete tables). An arbitrary number, which coincides with the number displayed in online tables is shown in the first column. The transition array, the multiplet and the wavelengths

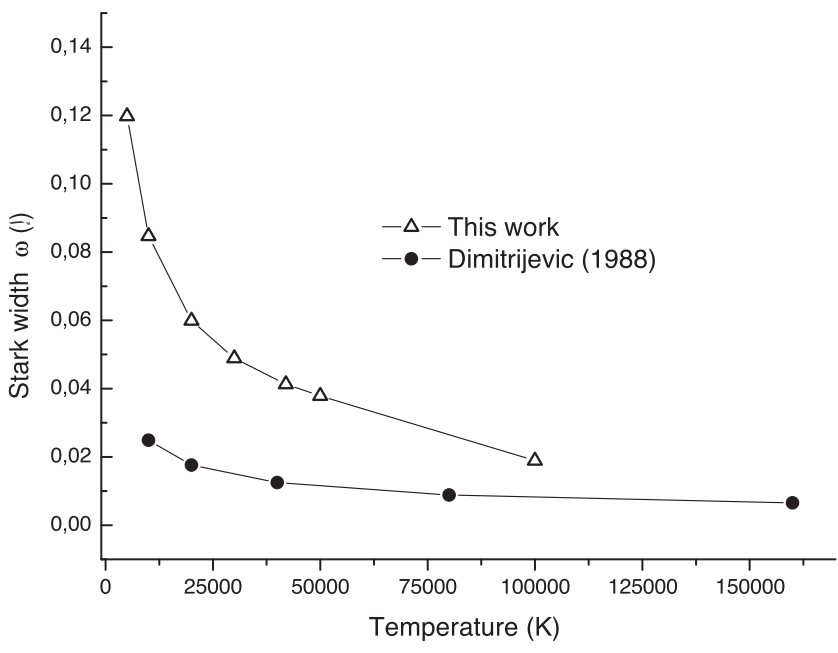

Figure 2. Calculated Stark width FWHM $(\omega(\AA))$, at a electron density of $10^{17} \mathrm{~cm}^{-3}$, versus temperature for $1683.00 \AA,\left(2 \mathrm{~s}^{2} 2 \mathrm{p}^{4}\left({ }^{3} \mathrm{P}\right) 3 \mathrm{~s}{ }^{4} \mathrm{P}_{5 / 2}\right.$ $\left.2 s^{2} 2 p^{4}\left({ }^{3} P\right) 3 p{ }^{4} D_{7 / 2}\right)$. Our values are compared with Dimitrijević (1988) values, which are also in the STARK-B Database.

(in $\AA$, Johannesson et al. 1972 and NIST), respectively for each studied transition are displayed in columns $2-4$ denote. In column fifth the temperatures in $\mathrm{K}$ are shown. Theoretical Stark broadening line-widths (in pm) are displayed in column sixth. The remaining column displays the theoretical Stark line-shift (a positive shift is 

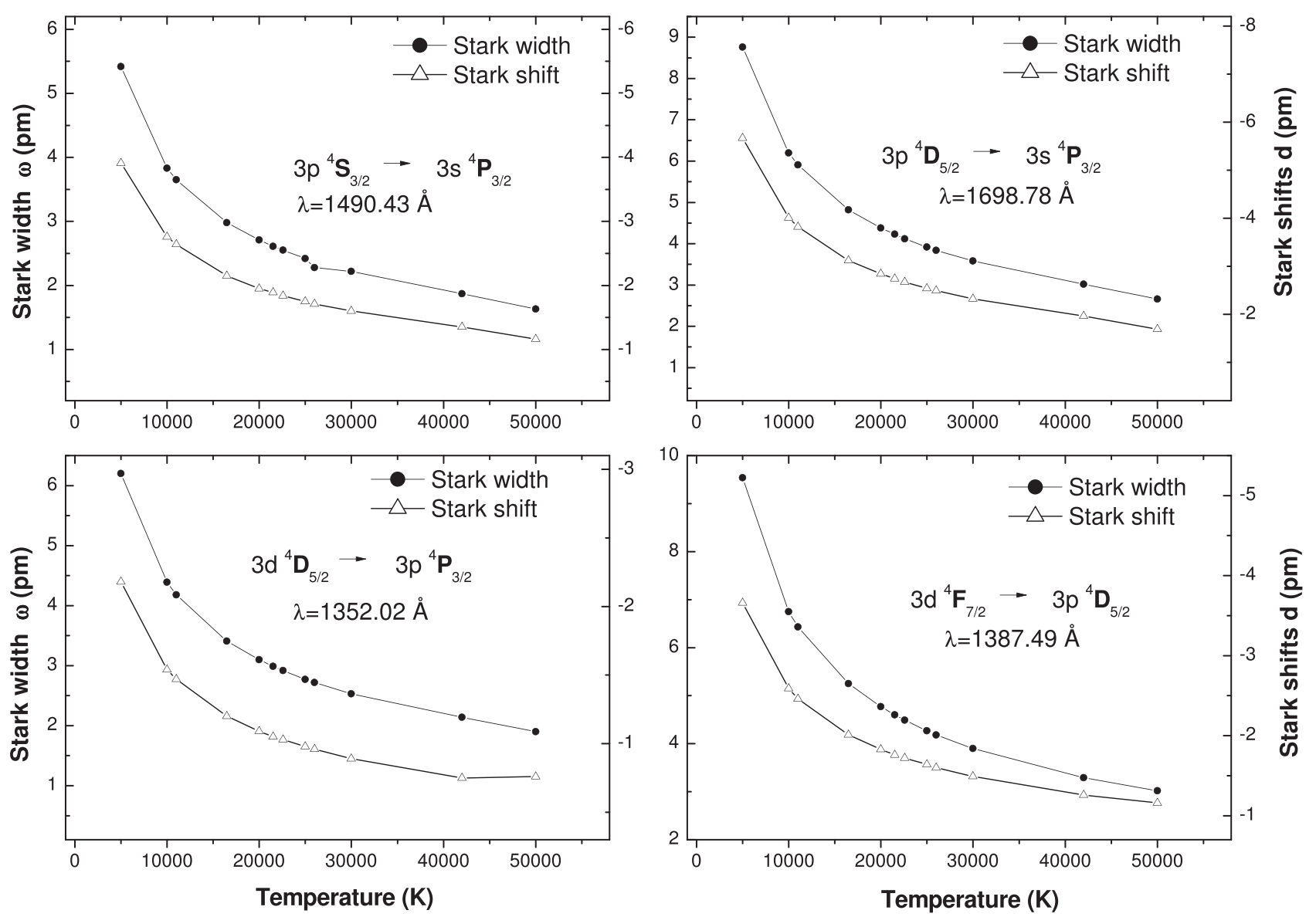

Figure 3. Calculated Stark width FWHM $(\omega(\mathrm{pm}))$ and Stark line shift $(\mathrm{d}(\mathrm{pm}))$ versus temperature for $1490.43 \AA$, $1698.78 \AA$, $1352.02 \AA$ and $1387.49 \AA \mathrm{Mg} \mathrm{IV}$ lines at a electron density of $10^{17} \mathrm{~cm}^{-3}$.

red). We have not found in the bibliography experimental values. We have found theoretical values calculated by other authors: four theoretical values for four Mg IV multiplets (Dimitrijević 1988). These values were calculated by using the Modified Semiempirical Method (MSE) by Sahal-Bréchot et al. (2014) and are included in the STARK-B Database (2013). Our results for several temperatures compared with MSE data for Stark Broadening of $1683.00 \AA$ spectral line are displayed in Fig. 2. In this figure to facilitate comparison with STARK-B Database; the results are presented in $\AA$. As usual, the calculations presented in this paper provide values higher than those provided by the MSE method values. Stark shifts for four resonant lines of $\mathrm{Mg}$ IV (180.07 $\AA, 180.79 \AA, 180.61 \AA$ and $181.34 \AA$ ) were observed by Ber̆gman, Pokrovskiŭ \& Ragozin (1996) as we mentioned above. The theoretical displacement for these lines calculated in this work is shown in the last column of Table 2 .

The dependence between the temperature and our widths FWHM $(\omega(\mathrm{pm}))$ as well as the dependence between the temperature and our Stark line shifts $(\mathrm{d}(\mathrm{pm}))$ are displayed, respectively in Fig. 3. $1490.43 \AA$, $1698.78 \AA, 1352.02 \AA$ and $1387.49 \AA \mathrm{Mg}$ IV lines were selected for its high astrophysical interest.

In conclusion, by using the semiempirical model of Griem, and the Cowan code to obtain the necessary matrix elements, we have calculated the Stark widths and shifts of $169 \mathrm{Mg}$ IV spectral lines. Our experience, as can be seen in the study of Sn III in Simić et al. (2008) and Alonso \& Colón (2011), is that the semiclassical method of Sahal-Bréchot (1969) and our semi empirical method gives analogous results and that both methods give values close to the experimental results within the margins of experimental error.

\section{ACKNOWLEDGEMENTS}

This work was financially supported by the Spanish DGI project MAT2012-37782.

\section{REFERENCES}

Alonso-Medina A., Colón C., 2011, MNRAS, 414, 713

Alonso-Medina A., Colón C., 2014, MNRAS, 445, 1567

Alonso-Medina A., Herrán C., 1996, Phys. Scr., 54, 332

Alonso-Medina A., Colón C., Montero J. L., Nation L., 2010, MNRAS, 401, 1080

Artru M. C., Kaufman V., 1972, J. Opt. Soc. Am., 62, 949

Artru M. C., Kaufman V., 1973, J. Opt. Soc. Am., 63, 449

Baranger M., 1958, Phys. Rev., 112, 855

Bĕgman I. L., Pokrovskiǔ Yu. Yu., Ragozin E. N., 1996, J. Exp. Theor. Phys., 83, 981

Bièmont E., 1985, Phys. Scr., 31, 45

Buchet J. P., Buchet-Poulizac M. C., Ceyzeriat P., 1980, Phys. Lett., 77, 424

Colón C., Alonso-Medina A., 2002, J. Phys. B: Atom. Mol. Opt. Phys., 35, 1143

Colón C., Alonso-Medina A., Rivero C., Fernández F., 2006, Phys. Scr., 73, 410

Colón C., Moreno-Díaz C., Alonso-Medina A., 2013, MNRAS, 435, 1749 
Cowan R. D., 1981, The Theory of Atomic Structure and Spectra. University of California Press, Berkeley, USA

de Andrés-García I., Alonso-Medina A., Colón C., 2016, MNRAS, 455, 1145

Dimitrijević M. S., 1988, A\&AS, 76, 53

Doschek G. A., Cowan R. D., 1984, ApJS, 56, 67

Fawcett B. C., 1984, At. Data Nucl. Data Tables, 31, 495

Froese Fischer Ch., Tachiev G., 2004, At. Data Nucl. Data Tables, 87, 152

Griem H. R., 1968, Phys. Rev., 165, 258

Gruzdev P. F., 1971, Opt. Spectrosc., 30, 319

Johannesson G. A., Lundström T., 1973, Phys. Scr., 8, 53

Johannesson G. A., Lundström T., Minnhagen L., 1972, Phys. Scr., 6, 129

Johnson C. T., Kingstom A. E., 1987, J. Phys. B: Atom. Mol. Opt. Phys., 20,5663

Kaufman V., Martin W. C., 1991, J. Phys. Chem. Ref. Data, 20, 83

Kramida A., Ralchenko Yu., Reader J., NIST ASD Team, 2013, NIST Atomic Spectra Database (v.5.3). Gaithersburg, MD, available at http://physics.nist.gov/asd.

Latour M., Fontaine G., Chayer P., Brassard P., 2013, ApJ, 773, 15

Lundi L., Engman B., Hilke J., Martinson I., 1973, Phys. Scr., 8, 274

Moore C. E., 1958, Atomic Energy Levels, NBS Circular 467, Vol. III. 213. Government Printing Office, Washington, DC

Moreno-Díaz C., Alonso-Medina A., Colón C., 2014, Phys. Scr., 89, 115401

Rauch T., Ziegler M., Werner K., Kruk J. W., Oliveira C. M., Vande Putte D., Mignani R. P., Kerber F., 2007, A\&A, 470, 317

Sahal-Bréchot S., 1969, A\&A, 1, 322

Sahal-Bréchot S., Dimitrijević M. S., Moreau N., 2013, STARK-B Database. l'Observatoire de Paris, Paris, available at https://stark-b.obspm.fr/

Sahal-Bréchot S., Dimitrijević M. S., Moreau N., Ben Nessib N, 2014, Adv. Space Res., 54, 1148
Seaton M. J., 1962, in Bates D. R., ed., Atomic and Molecular Processes. New York Academic, New York

Simić Z., Dimitrijević M. S., Kovačević A., Dačić M., 2008, Publ. Astron. Obs. Belgr., 84, 487

Van Regemorter H., 1962, ApJ, 136, 906

\section{SUPPORTING INFORMATION}

Additional Supporting Information may be found in the online version of this article:

Table 2. $M g$ IV $2 s^{2} 2 p^{5}-2 s^{2} 2 p^{4}\left({ }^{3} P\right) 3 s$ and $2 s^{2} 2 p^{5}-2 s^{2} 2 p^{4}\left({ }^{1} D\right) 3 s$ linewidths (FWHM), $\omega(\mathrm{pm})$, and shifts, $d(\mathrm{pm})$, normalized to $\mathrm{Ne}=$ $10^{17} \mathrm{~cm}^{-3}$.

Table 3. $\mathrm{Mg}$ IV $2 \mathrm{~s}^{2} 2 \mathrm{p}^{4}\left({ }^{3} \mathrm{P}\right) 3 \mathrm{~s}-2 \mathrm{~s}^{2} 2 \mathrm{p}^{4}\left({ }^{3} \mathrm{P}\right) 3 \mathrm{p}$ line-widths (FWHM), $\omega$ $(\mathrm{pm})$, and shifts, $d(\mathrm{pm})$, normalized to $\mathrm{Ne}=10^{17} \mathrm{~cm}^{-3}$.

Table 4. Mg IV $2 s^{2} 2 p^{4}\left({ }^{3} \mathrm{P}\right) 3 \mathrm{p}-2 \mathrm{~s}^{2} 2 \mathrm{p}^{4}\left({ }^{3} \mathrm{P}\right) 3 \mathrm{~d}$ line-widths (FWHM), $\omega(\mathrm{pm})$, and shifts, $d(\mathrm{pm})$, normalized to $N e=10^{17} \mathrm{~cm}^{-3}$. (http://www.mnras.oxfordjournals.org/lookup/suppl/doi:10.1093/ mnras/stw1955/-/DC1).

Please note: Oxford University Press is not responsible for the content or functionality of any supporting materials supplied by the authors. Any queries (other than missing material) should be directed to the corresponding author for the article.

This paper has been typeset from a $\mathrm{T}_{\mathrm{E}} \mathrm{X} / \mathrm{L} \mathrm{T}_{\mathrm{E}} \mathrm{X}$ file prepared by the author. 